\title{
Effect of Machining Parameters on Surface Roughness During Milling Operation
}

\author{
Sajid Raza Zaidia, ${ }^{\mathrm{a}}$, Mushtaq Khan ${ }^{\mathrm{a}}$, Syed Husain Imran Jaffery ${ }^{\mathrm{a}}$, Salman Sagheer \\ Warsi ${ }^{\mathrm{b}}$

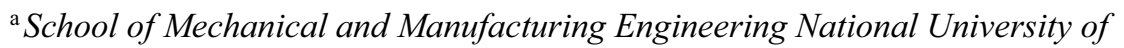 \\ Sciences and Technology Islamabad \\ ${ }^{\mathrm{b}}$ Department of Mechanical Engineering Capital University of Science and \\ Technology, Islamabad
}

\begin{abstract}
Aluminum is one of the most extensively used metal in aerospace industry and other applications due to its corrosion resistance, good machineability excellent mechanical properties and high strength to weight ratio. Machining parameters like number of inserts, depth of cut, cutting speed, feed rate, and cutting tool diameter have considerable impact on production rate, surface finish, energy consumption and sustainable machining. Suitable process parameters during machining and specifically milling process not only leads towards better surface finish but also towards sustainable machining. Aim of machining has always been to produce parts with better surface quality and lower energy consumption. To study the effect of milling parameters on the surface finish, Taguchi L9 array was employed for experimentation. The outcome of each parameter on surface finish has been examined using ANOVA and the most considerable parameters were identified. It has also been observed that the number of inserts significantly influence the surface finish.
\end{abstract}

Keywords. Surface Roughness, ANOVA, Milling Machine.

\section{Introduction}

To obtain the desired geometry and shape most widely used machining operations are milling, drilling, and turning. Possibility of creating diversity of shapes and better production yield makes milling one of the most frequently utilized machining process [1]-[3]. Milling is interrupted cutting operation as the cutting tool can have one or more than one cutting edge which engages the work piece [2]. Machining parameters that can be varied during the milling operation includes width of cut, depth of cut, number of inserts, feed, cutting speed, type of lubricant, tool material, inserts geometry and tool diameter [4]-[6].

Surface roughness has most important role in surface topography and other mechanical properties of a part like fatigue life and tensile strength [7]-[11]. Beside influencing the properties and functioning of the machined components surface roughness is additionally one of the major parameter of dimensional accuracy [3]. Geometric factors, machine tool factors and work piece material are the three factors affecting the surface roughness of

\footnotetext{
${ }^{1}$ Corresponding Author. sajidzaidi.pg@smme.edu.pk
} 
any part or component. Geometric factors affecting the surface roughness includes type of machining operation, feed rate and cutting tool geometry [12].

By using appropriate machining parameters, required surface finish can be attained. However, surface finish can be adjusted, improved and predicted depending upon the selection of geometric factors which includes width of cut, depth of cut, cutting velocity, feed per tooth, and type of machining operation [13]-[22]. In comparison to wet machining MQL shows better surface finish [23]. In the published literature feed rate and depth of cut performs the most significant part in generating surface roughness [24], [25]. Improved surface finish can be attained by increasing cutting velocity and by decreasing feed [25]-[28].

\section{Experiment Design and Material Selection}

This experimental study is performed on MV-1060 YDPM milling machine using Sandvik end mill cutter of $25 \mathrm{~mm}$ diameter and surface roughness $(\mu \mathrm{m})$ is measured using TIME® 3110 roughness tester. As recommended by past research, key process variables can be established using Taguchi's methodology by designing experiments using orthogonal arrays to reduce production costs and improve quality [29]. Taguchi L9 array is employed for design of experiments. Number of inserts, cutting velocity, depth of cut and feed/tooth are varied in 3 intervals. Unified milling experiments using the same workpiece material supplied from the same stock and using the same cutting inserts supplied by Sandvik were used as recommended by past researchers [30, 31]. The machining parameters are shown in table III. Workpiece material is aluminium 6061-T6. Inserts and cutting tool is selected using Sandvik catalogue. Chemical and mechanical properties of aluminium 6061-T6 are shown in table I and cutting tool and inserts specifications are displayed in table II.

Table I: Chemical and mechanical properties of aluminium 6061-T6 [30]

\begin{tabular}{|l|l|l|l|l|l|l|l|l|l|}
\hline & $\mathrm{Si}$ & $\mathrm{Fe}$ & $\mathrm{Cu}$ & $\mathrm{Mn}$ & $\mathrm{Mg}$ & $\mathrm{Cr}$ & $\mathrm{Zn}$ & $\mathrm{Ti}$ & $\mathrm{Al}$ \\
\hline$\%$ & 0.62 & 0.22 & 0.29 & 0.07 & 1.1 & 0.18 & 0.01 & 0.01 & $\sim \mathrm{Bal}$ \\
\hline
\end{tabular}

Table II: Tool Holder, End mill cutter and inserts specifications.

\begin{tabular}{|l|l|}
\hline Specifications & Descriptions \\
\hline Tool holder & WALTER A170M.063.080.25 \\
\hline End mill cutter & R390-0.25B25-11M \& R390-028B25-11L \\
\hline Insert & R390-11 T3 02E-KM H13A \\
\hline Tool diameter & $25 \mathrm{~mm}$ \\
\hline $\begin{array}{l}\text { Maximum cutting velocity (m/min) of } \\
\text { insert }\end{array}$ & 1000 \\
\hline Feed per tooth (mm/tooth) & $0.08-0.18$ \\
\hline
\end{tabular}

Machining parameters are varied and their effect on surface roughness is analysed using ANOVA at $95 \%$ confidence level (significance level for $\alpha=0.05$ ). Factor whose P-value is below 0.05 was considered significant. 
Table III: Levels of machining parameters used in this study.

\begin{tabular}{cccc}
\hline Depth of Cut (mm) & Cutting Speed (m/min) & $\begin{array}{c}\text { Feed per Tooth } \\
\text { (mm/tooth) }\end{array}$ & $\begin{array}{c}\text { Number of } \\
\text { Inserts }\end{array}$ \\
\hline 1 & 325 & 0.1 & 1 \\
1.5 & 350 & 1.4 & 2 \\
2 & 375 & 1.8 & 3 \\
\hline
\end{tabular}

\section{Results and Discussion}

Main effect plots for average surface roughness are presented in figure I and results of ANOVA are shown table IV. Figure I show that average surface roughness increase with the decrease in depth of cut and average surface roughness increases with the increase in the cutting speed, feed per tooth and number of flutes (inserts).

P-value for all the factors is less than 0.05 which means that these machining parameters are significant for average surface roughness.

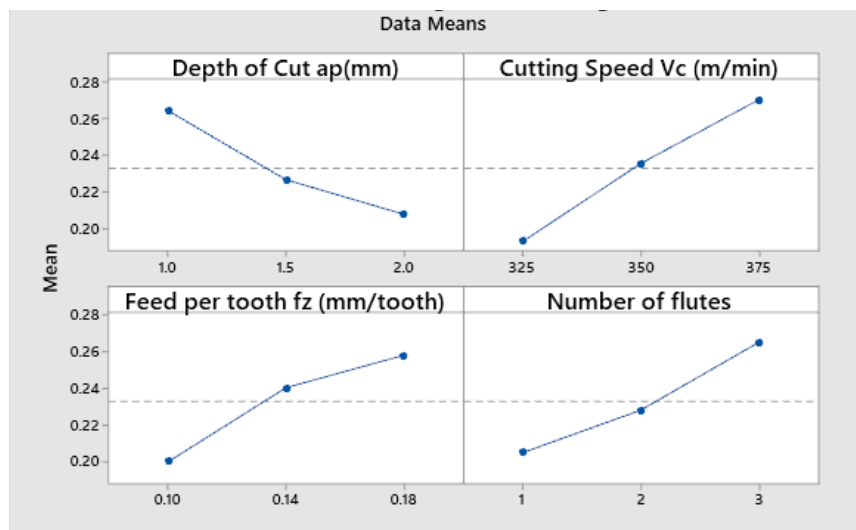

Figure I: Main Effect Plots for Average Surface Roughness

Table IV. ANOVA results for this study

\begin{tabular}{crrrrr}
\hline \multicolumn{1}{c}{ Source } & DF & \multicolumn{1}{c}{ Adj SS } & \multicolumn{1}{c}{ Adj MS } & F-Value & P-Value \\
\hline Depth of Cut ap $(\mathrm{mm})$ & 2 & 0.009990 & 0.004995 & 7.14 & 0.014 \\
Cutting Speed $\mathrm{V}_{\mathrm{c}}(\mathrm{m} / \mathrm{min})$ & 2 & 0.018209 & 0.009104 & 13.01 & 0.002 \\
Feed per tooth fz $(\mathrm{mm} /$ tooth $)$ & 2 & 0.010727 & 0.005364 & 7.66 & 0.011 \\
Number of flutes & 2 & 0.011194 & 0.005597 & 8.00 & 0.010 \\
$\quad$ Error & 9 & 0.006300 & 0.000700 & & \\
Total & 17 & 0.056420 & & & \\
\hline
\end{tabular}

\section{Conclusion}

From this experimental analysis it is concluded that surface finish is highly dependent on machining parameters which are number of inserts, feed per tooth, cutting speed and depth of cut. 
- With a decrease in depth of cut average surface roughness $(R a)$ increases. So, to obtain better surface finish, higher values of depth of cut should be selected.

- Average surface roughness rises with the greater number of inserts, feed per tooth and cutting velocity/speed. So, greater values of above said parameters should be used for better surface finish.

- $\quad$ Results of ANOVA shows that all machining parameters which are cutting velocity/speed, depth of cut, feed/tooth and number of inserts plays significant role in generation of surface roughness.

- By using suitable machining parameters, better surface finish can be achieved.

\section{References}

[1] M. P. Groover, Fundamental of Modern Manufacturing Material, Processes, and System Fifth Edition. 2012.

[2] M. C. Shaw, METAL CUTTING PRINCIPLES, Second Edi., no. June. Oxford University Press, 2001.

[3] S. R. S. Serope Kalpakjian, Manufacturing engineering and technology, 6th ed. 2010.

[4] K. Kumar, D. Zindani, and J. P. Davim, Introduction to Machining Processes. 2018.

[5] E. M. Trent and P. K. Wright, Metal Cutting Fourth Edition. 2000.

[6] E. T. \& P. Wright, Metal-Cutting., 4th ed. 2000.

[7] D. Arola and C. L. Williams, "Estimating the fatigue stress concentration factor of machined surfaces," Int. J. Fatigue, vol. 24, no. 9, pp. 923-930, Sep. 2002, doi: 10.1016/S0142-1123(02)00012-9.

[8] A. Javidi, U. Rieger, and W. Eichlseder, "The effect of machining on the surface integrity and fatigue life," Int. J. Fatigue, vol. 30, no. 10-11, pp. 2050-2055, 2008, doi: 10.1016/j.ijfatigue.2008.01.005.

[9] L. Chen and X. Zhang, "Modification the surface quality and mechanical properties by laser polishing of Al/PLA part manufactured by fused deposition modeling," Appl. Surf. Sci., vol. 492, pp. 765-775, Oct. 2019, doi: 10.1016/j.apsusc.2019.06.252.

[10] M. Kiliç, E. Burdurlu, S. Aslan, S. Altun, and Ö. Tümerdem, "The effect of surface roughness on tensile strength of the medium density fiberboard (MDF) overlaid with polyvinyl chloride (PVC)," Mater. Des., vol. 30, no. 10, pp. 45804583, Dec. 2009, doi: 10.1016/j.matdes.2009.03.029.

[11] S. R. Zaidi, "Effect of Laser Surface Melting on Fatigue Life of Aluminium 6061-T6," MS Thesis, 2017.

[12] "Mikell P. Groover Fundamentals of Modern Manufacturing Materials, Processes, and Systems, Fourth Edition 2010.pdf." pp. 1-1028, 2016.

[13] M. A. Khan et al., "Statistical analysis of energy consumption, tool wear and surface roughness in machining of Titanium alloy (Ti-6Al-4V) under dry, wet and cryogenic conditions," Mech. Sci., vol. 10, no. 2, pp. 561-573, 2019, doi: 10.5194/ms-10-561-2019.

[14] D. Vakondios, P. Kyratsis, S. Yaldiz, and A. Antoniadis, "Influence of milling 
strategy on the surface roughness in ball end milling of the aluminum alloy Al7075-T6," Meas. J. Int. Meas. Confed., vol. 45, no. 6, pp. 1480-1488, 2012, doi: 10.1016/j.measurement.2012.03.001.

[15] P. Haja Syeddu Masooth, V. Jayakumar, and G. Bharathiraja, "Experimental investigation on surface roughness in $\mathrm{CNC}$ end milling process by uncoated and TiAlN coated carbide end mill under dry conditions," Mater. Today Proc., vol. 22, pp. 726-736, 2020, doi: 10.1016/j.matpr.2019.10.036.

[16] R. Sanjeevi, R. Nagaraja, and B. Radha Krishnan, "Vision-based surface roughness accuracy prediction in the CNC milling process (A16061) using ANN," Mater. Today Proc., no. xxxx, 2020, doi: 10.1016/j.matpr.2020.05.122.

[17] C. Agrawal, J. Wadhwa, A. Pitroda, C. I. Pruncu, M. Sarikaya, and N. Khanna, "Comprehensive analysis of tool wear, tool life, surface roughness, costing and carbon emissions in turning Ti-6Al-4V titanium alloy: Cryogenic versus wet machining," Tribol. Int., vol. 153, p. 106597, Jan. 2021, doi: 10.1016/j.triboint.2020.106597.

[18] G. Kiswanto, D. L. Zariatin, and T. J. Ko, "The effect of spindle speed, feed-rate and machining time to the surface roughness and burr formation of Aluminum Alloy 1100 in micro-milling operation," J. Manuf. Process., vol. 16, no. 4, pp. 435-450, 2014, doi: 10.1016/j.jmapro.2014.05.003.

[19] A. Sharma and V. K. Dwivedi, "Effect of milling parameters on surface roughness: An experimental investigation," Mater. Today Proc., vol. 25, pp. 868-871, 2019, doi: 10.1016/j.matpr.2019.11.256.

[20] N. Liu, S. B. Wang, Y. F. Zhang, and W. F. Lu, "A novel approach to predicting surface roughness based on specific cutting energy consumption when slot milling Al-7075," Int. J. Mech. Sci., vol. 118, pp. 13-20, Nov. 2016, doi: 10.1016/j.ijmecsci.2016.09.002.

[21] M. Kuttolamadom, S. Hamzehlouia, and L. Mears, "Effect of machining feed on surface roughness in cutting 6061 aluminum," SAE Tech. Pap., vol. 3, no. 1, pp. 108-119, 2010, doi: 10.4271/2010-01-0218.

[22] A. A. Premnath, T. Alwarsamy, T. Abhinav, and C. A. Krishnakant, "Surface roughness prediction by response surface methodology in milling of hybrid aluminium composites," Procedia Eng., vol. 38, pp. 745-752, 2012, doi: 10.1016/j.proeng.2012.06.094.

[23] M. Syahmi, N. Mat, Y. Ahmad, and R. Yusoffa "Taguchi Method Approach on Effect of Lubrication Condition on Surface Roughness in Milling Operation," vol. 53, pp. 594-599, 2013, doi: 10.1016/j.proeng.2013.02.076.

[24] Z. Wang and L. Li, "Optimization of process parameters for surface roughness and tool wear in milling TC17 alloy using Taguchi with grey relational analysis," Adv. Mech. Eng., vol. 13, no. 2, pp. 1-8, 2021, doi: 10.1177/1687814021996530.

[25] K. V. M. K. Raju, G. R. Janardhana, P. N. Kumar, and V. D. P. Rao, "Optimization of cutting conditions for surface roughness in CNC end milling," Int. J. Precis. Eng. Manuf., vol. 12, no. 3, pp. 383-391, 2011, doi: 10.1007/s12541-011-0050-7.

[26] A. a Thakre, "Optimization of Milling Parameters for Minimizing Surface Roughness Using Taguchi 's Approach,” Int. J. Emerg. Technol. Adv. Eng., vol. 3, no. 6, pp. 1-5, 2013.

[27] N. Tosun and M. Huseyinoglu, "Effect of MQL on surface roughness in milling of AA7075-T6," Mater. Manuf. Process., vol. 25, no. 8, pp. 793-798, 2010, doi: 10.1080/10426910903496821. 
[28] M. Y. Wang and H. Y. Chang, "Experimental study of surface roughness in slot end milling AL2014-T6," Int. J. Mach. Tools Manuf., vol. 44, no. 1, pp. 51-57, 2004, doi: 10.1016/j.ijmachtools.2003.08.011.

[29] Jaffery, S. I., N. Driver, and P. T. Mativenga. "Analysis of process parameters in the micromachining of Ti-6Al-4V alloy." In Proc. of the 36th Intl. MATADOR Conf., pp. 239-242. Springer, London, 2010.

[30] Jaffery, S. I., and P. T. Mativenga. "Study of the use of wear maps for assessing machining performance." IMechE-B - J. of Engg Manuf. vol. 223, no. 9, pp. 1097-1105, 2009.

[31] S. S. Warsi, H. I. Jaffery, R. Ahmad, M. Khan, and S. Akram, “Analysis of Power and Specific Cutting Energy Consumption in Orthogonal Machining of Al 6061T6 Alloys at Transitional Cutting Speeds," p. V02BT02A057, 2016, doi: 10.1115/imece2015-53290. 